\title{
Retentive strength of fiber-reinforced composite posts with composite resin cores: Effect of remaining coronal structure and root canal dentin conditioning protocols
}

\author{
Saker, Samah ; Özcan, Mutlu
}

\begin{abstract}
STATEMENT OF PROBLEM The prognosis of a fixed dental prosthesis cemented to endodontically treated teeth is primarily determined by the presence of a ferrule on the tooth. Adhesion of the post in the root canal, conditioning methods for the canal and the amount of coronal structure could also be decisive on survival of reconstructions cemented on endodontically treated teeth. PURPOSE The purpose of this in vitro study was to test the effect of remaining coronal structure on the retention of airborne-particle abraded fiberreinforced composite resin posts built up with composite resin cores after the treatment of root canal dentin with different conditioning protocols. MATERIAL AND METHODS One hundred and fifty extracted human teeth with single root canal space were endodontically treated and divided into 3 groups as follows: group CEJ: the teeth were sectioned at the level of cementoenamel junction (CEJ); group CEJ1: the teeth were sectioned 1 $\mathrm{mm}$ above the CEJ; group CEJ2: the teeth were sectioned $2 \mathrm{~mm}$ above the CEJ. Each group was further divided into 5 subgroups ( $n=10$ per group) according to the root canal treatments as follows: group C: no conditioning (control); group PH: conditioning with 37\% phosphoric acid gel for 15 seconds; group E: conditioning with $17 \%$ ethylenediaminetetraacetic acid (EDTA) for 60 seconds; group CHX: conditioning with 2\% chlorhexidine (CHX) for 60 seconds; group Q: conditioning with combination of $2 \%$ CHX with 17\% EDTA and a surfactant solution for 60 seconds. Glass fiber-reinforced composite resin posts were airborne-particle abraded and luted to the root canal dentin with a self-adhesive resin cement (RelyX Unicem). The retentive force was tested by applying a tensile load parallel to the long axis of these posts at a crosshead speed of $2 \mathrm{~mm} / \mathrm{min}$. Two-way ANOVA and the Tukey HSD post hoc test were used to analyze the data. RESULTS The highest retention (N) was obtained with the CHX-EDTA conditioned group $(374.7 \pm 29.8)$ followed by $17 \%$ EDTA $(367.9 \pm 33.3)$ conditioning when 2 $\mathrm{mm}$ remaining coronal structure was available. Conditioning with the CHX-EDTA showed comparable retention values to $17 \%$ EDTA conditioned groups when 0 or $1 \mathrm{~mm}$ coronal structure was present that differed significantly compared to $37 \% \mathrm{PH}$ and $2 \% \mathrm{CHX}$ conditioning $(\mathrm{P}<.05)$. CONCLUSIONS Conditioning root canal either with CHX-EDTA or 17\% EDTA delivered superior retention values for fiber-reinforced composite resin posts with composite resin cores that were luted with self-adhesive resin cement to endodontically treated teeth with $2 \mathrm{~mm}$ remaining coronal structure.
\end{abstract}

DOI: https://doi.org/10.1016/j.prosdent.2015.06.015

Posted at the Zurich Open Repository and Archive, University of Zurich ZORA URL: https://doi.org/10.5167/uzh-116041

Journal Article Accepted Version

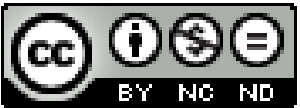


The following work is licensed under a Creative Commons: Attribution-NonCommercial-NoDerivatives 4.0 International (CC BY-NC-ND 4.0) License.

Originally published at:

Saker, Samah; Ȯzcan, Mutlu (2015). Retentive strength of fiber-reinforced composite posts with composite resin cores: Effect of remaining coronal structure and root canal dentin conditioning protocols. Journal of Prosthetic Dentistry, 114(6):856-61.

DOI: https://doi.org/10.1016/j.prosdent.2015.06.015 
Retentive Strength of Fiber-Reinforced Posts with Composite Resin Cores : Effect of

Remaining Coronal Structure, Root Canal Conditioning and Luting Resin Cement.

\section{Samah Saker, BDS, MSc, PhD * \\ Mutlu Özcan ${ }^{b}$}

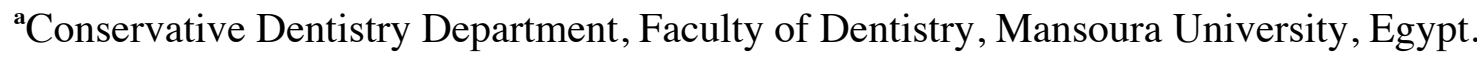

${ }^{b}$ University of Zürich, Dental Materials Unit, Center for Dental and Oral Medicine Clinic for Fixed anc

Removable Prosthodontics and Dental Materials Science, Plattenstrasse 11, CH-8032, Zürich, Switzerland

*Correspondance:

Dr. Samah Saker

Address: 35516 El Gomhoria Street, Conservative Dentistry Department, Faculty of Dentistry, Mansoura University, Egypt. Tel : +201287457890 .E-mail: samah_saker@hotmail.com. 


\begin{abstract}
Purpose. The purpose of this study was to test the effect of remaining coronal structure on the retention of abraded fiber-reinforced composite resin posts with composite resin cores that are luted with 3 different bonding systems after treatment of root canal dentin with different conditioning methods.
\end{abstract}

Material and Methods. Teeth with single roots that were endodontically treated recruited in this study and divided into 3 groups as follow: Group 1 , the teeth were sectioned at the level CEJ, Group 2, the teeth were sectioned $1 \mathrm{~mm}$ above the CEJ, Group 2, the teeth were sectioned $2 \mathrm{~mm}$ above the CEJ. Each group was divided into 5 subgroups ( $\mathrm{n}=20$ each) according to root canal treatments as follow: Group C, received no treatment (Control); Group P, treated with 37\% phosphoric acid gel for $15 \mathrm{sec}$; Group E, treated with 17\% EDTA for $60 \mathrm{sec}$; Group CH, treated with 2\% Ch for $60 \mathrm{sec}$; Group Q, treated with QMiX for $60 \mathrm{sec}$. Each treatment group was further classified into 2 subgroups ( $\mathrm{n}=10$ each) according to the luting cement type used. Glass fiber-reinforced composite resin posts were abraded and luted to the root canal dentin using either Rely X Unicem self-adhesive or Panavia F2 self-etch resin cement. The retentive force was tested by applying tensile load parallel to the long axis of these posts at a crosshead speed of $1 \mathrm{~mm} / \mathrm{min}$. Three-way ANOVA was employed to analyse the data.

Results. The highest retentive strength values measured with the QMiX -treated group with 2 mm remaining coronal structure luted with Rely X Unicem self-adhesive and Panavia F2 selfetch resin cement, $\mathrm{N}$ and $\mathrm{N}$, respectively. Treatments with QMiX and 17\% EDTA showed comparable retentive values that differed significantly $(\mathrm{P} \leq .05)$ compared to $37 \%$ phosphoric 
acid. Self-etch resin cement significantly increased the retentive values of fiber-reinforced composite resin posts as compared to self-adhesive cement.

Conclusions. QMiX and 17\% EDTA treatments produce superior retentive values of fiberreinforced composite resin posts with composite resin cores that are luted with self-etch resin cement to endodontically treated teeth with $2 \mathrm{~mm}$ remaining coronal structure .

Key words: Retention, Root Canal Dentin Conditioning, EDTA, Lactic Acid, Phosphoric Acid.

CLINICAL IMPLICATIONS: Conditioning root canal dentin with either QMiX or 17\% EDTA before cementation with resin cement may enhance post/dentin retention. Bonding of fiber-reinforced composite resin posts and cores to endodontically treated teeth with $2 \mathrm{~mm}$ remaining coronal structure using self-etch resin cement produced high retentive strength compared to self-adhesive resin cement.

\section{INTRODUCTION}

Most of clinicians face great challenge in restoring the root canal-treated teeth. This challenge is dependant mainly on the extent of the loss in the coronal tooth structure due to caries, defective restoration and root canal access preparations. The restoration of endodontically treated teeth with a significant loss of coronal tooth structure may require the placement of a post to ensure an adequate retention of a core foundation. ${ }^{1-4}$ Prefabricated posts with composite resin cores are commonly being used for their acceptable results at reduced costs and save time. Glass fiber-reinforced composite resin post systems have inherent advantages with respect to their biomechanical properties, 
and their property of increasing light transmission through the root and the gingiva tissue overlying it. ${ }^{5-7}$ In addition, they are easy to remove in the event of treatment failure, ${ }^{8}$ eliminate the potential risk of corrosion and allergic reactions associated with metal posts, ${ }^{9}$ and have a low modulus of elasticity that has been reported to reduce root fracture. ${ }^{10,11}$ Glass-fiber composite resin posts are formed of "glass fibers, inorganic filler, and resin matrix." Resin cement is usually used to lute these posts in order to increase their retentive strength and improve the functional performance of the tooth being restored. ${ }^{12}$ Failure of fiber posts is mainly related to debonding that usually occurs along the post/dentin adhesive interface. Many factors may influence the retention of resin cement-luted posts; ${ }^{13}, 14$ the irrigant used in the root canal preparation, ${ }^{15}$ thick smear layer and the configuration factor defined as the ratio of bonded to unbonded surfaces in post preparations. ${ }^{16}$ Treatment of the smear layer before post cementation may be important for achieving high retentive strength levels. The primary objective of applying these agents is to merge the smear layer into the hybrid layer ${ }^{17}$ and facilitate the penetration of adhesives into the dentinal tubules to form an inter-diffusion zone between the adhesive material and etched dentin. ${ }^{18-20}$

The use of $35 \%$ phosphoric acid in conditioning root dentin prior to luting with an autoadhesive was reported to be ineffective or even harmful. ${ }^{21,22}$ The use of less acidic agents like EDTA or lactic acid was considered. ${ }^{23-27}$ These acidic treatments enhance the chemical bonding between the luting cement and the substrate by partial elimination of the smear layer, leaving the dentin mineral phase. ${ }^{26,28}$ Recently, QMiX was introduced for root canal irrigation ${ }^{29}$. Its manufacturer recommends that it should be used at the end of instrumentation after $\mathrm{NaOCl}$ irrigation. QMiX contains EDTA, CHX, and a detergent and comes as a ready-to-use clear solution.

The use of self-adhesive resin cements was recommended for fiber-reinforced composite resin posts cementation, as its application is simple and saves chair-time. ${ }^{29}$ however, the need to 
enhance cement/dentin interaction and bond strength accordingly, the smear layer should be eliminated using an acidic conditioning material. ${ }^{30,31}$ Clinical studies reported that for restorations placed with adhesively luted fiber posts, failure most commonly occurred due to debonding of the post .$^{32,33}$ As the most common reason for fiber-reinforced post failure is the dislodgement of the post out of the root canal that might occur after years as a result of dynamic mechanical loading. ${ }^{34}$ It is generally agreed that post retention is the major factor in survival of restorations so many studies have focused on post retention improvement, including use of different endodontic irrigants, ${ }^{35-37}$ pretreatment of the posts ${ }^{38,39}$ post configuration, ${ }^{40}$ and dentin ${ }^{40-43}$ or use of various luting cements. ${ }^{44,45}$ However, the study of the effect of remaining coronal stracture, the ideal surface conditioning of the root dentin and the resin cement needed to improve the retentive bond strength have not been verified yet. Therefore, this study aimed to to test the null hypothesis that both of remaining coronal tooth structure and dentin pretreatment have no influence on the retention of fiber-reinforced composite resin posts with composite resin cores that are luted with different types of luting resin cements.

\section{MATERIALS AND METHODS}

\section{$\underline{\text { Root canal obturation }}$}

Eighty extracted human maxillary anterior teeth were obtained for this study from periodontitis patients with grade III mobility after informed consent. Approval to use human teeth was obtained from the Research Ethics Committee at the Faculty of Dentistry, Mansoura University, Egypt. Power analysis was performed before conducting this study 'a priori' using SAS/STAT software to determine the number of specimens required in each test group in order to determine if statistical differences existed among groups. Teeth selected for this study were caries-free, fracture-free as assessed visually, have straight root, with one round root canal and fully developed 
apices. The teeth were then cleaned and debrided of calculus deposits and soft tissues then stored in $0.1 \%$ thymol solution at $4^{\circ} \mathrm{C}$ to be used in 3 months following extraction at the maximum.

The teeth were randomly assigned to 3 groups $(n=40)$ based on the amount of remaining coronal stracture to , Group 1; Anatomical crowns were transversely sectioned at the level of cemento-enamel junction (CEJ) using a diamond rotary cutting instrument (837KR.012; Gebr Brasseler GmbH, Lemgo, Germany) under water spray. The section surface was flattened to be perpendicular to the longitudinal axis of the tooth using $\mathrm{SiC}$ sand paper (600-grit). Group 2; Anatomical crowns were transversely sectioned at $1 \mathrm{~mm}$ coronal to the cement enamel junction (CEJ) as described before. Group 3; Anatomical crowns were transversely sectioned at $2 \mathrm{~mm}$ coronal to the cemento-enamel junction (CEJ) as described before.

Afterward,a barbed broach was used to remove the pulpal tissue. Canal patency was examined by passing $10 \mathrm{~K}$-file (Dentsply Maillfer CH. 1338 Ballalgues-Switzerland) through the tooth apical foramen. Canal working length was fixed to be $1.0 \mathrm{~mm}$ shorter from the apical foramen. A step-back technique was employed in this study during root canal preparation. The same operator performed all root canal preparations using a final file size number 55 (DentsplyMaillefer). In the process of canal shaping, a 5.25\% sodium hypochlorite irrigant was used after each file and up to the final size used, followed by rinsed with distilled water then the canals were dried using paper points (Dentsply-Maillefer, Ballaigues, Switzerland). Canals were then obturated employing the lateral condensation technique with gutta-percha cones (DentsplyMaillefer) and sealer (AH-Plus; Dentsply DeTrey GmbH, Konstanz, Germany). Following obturation, the cervical root canal openings were closed with a temporaty restorative material 
(Cavit-G; 3M ESPE AG, Seefeld, Germany), and the teeth were stored at $37^{\circ} \mathrm{C}$ for 7 days in $100 \%$ humid conditions.

\section{Posts space preparation}

All the teeth in group 2 and 3 received $1.2 \mathrm{~mm}$ butt shoulder preparation with rounded inner angles. The preparations had a convergence of 6 degrees. The finish line of each preparation was at the CEJ. Post space was prepared to the depth of $10 \mathrm{~mm}$ from the CEJ, and an apical seal of $4 \mathrm{~mm}$ of gutta-percha was left untouched. A warm plugger (Sybron Dental Specialties, Romulus, Mi) was used to remove gutta-percha up to the decided depth. To enlarge the root canals a low-speed drill, provided the same manufacturer of the post system, was used. A final flush of sterile water to clean the canal space then paper points (Dentsply-Maillefer) were used to dry the canal.

\section{Root canal dentin conditioning}

The prepared root canals were divided into 4 groups ( $\mathrm{n}=20$ each) according to dentin conditioning protocol: 1) Group C; root canals received no pretreatment and was considered as a control. 2) Group P; 37\% phosphoric acid gel (Total Etch, Ivoclar Vivadent) was used to etch the root canals for 15 seconds using a syringe and applicator tip followed by an irrigation step with distilled water to remove the etchant excess then canals were dried with paper points. 3) Group E; root canals were rinsed with $17 \%$ EDTA (Ethylenediaminetetraacetic acid, Pulpdent, Watertown, Ma) for 60 seconds, rinsed with water and dried using paper points. 4) Group $\mathrm{CH}$, root canals were rinsed with 2\% CHX (Gluco-CheX 2,0\%, PPH Cerkamed, UL, Sandomierska, BB, Poland); root canals were rinsed with 5) Group Q; root canals were rinsed with QMix (Dentsply Tulsa Dental, Tulsa, OK, USA)for 60 seconds, irrigated with water and dried using paper 
points. Each group was further divided into 2 subgroups ( $\mathrm{n}=10$ each) according to the luting agent used: 1) Subgroup A: posts were luted with Rely X Unicem self-adhesive resin cement. 2) Subgroup B: posts were luted with Panavia F2 self-etch resin cement.

\section{Posts and cores preparation}

Fiber-reinforced Postec Plus posts ((Ivoclar Vivadent, Schaan, Liechtenstein) of $1.4 \mathrm{~mm}$ diameter were selected. Each post was mounted on a custom made revolving wheel where each of the post four sides surface was abraded with $50 \mathrm{~mm}$ airborne alumina particles (Heraeus Kulzer) at 2.5 bar pressure ( 36.3 psi) for 5 seconds. Each resin cement type was mixed and applied following the manufacturers' instructions, (Table. I). Posts were inserted in a custom made holder mounted on a surveyor; the apical 2 thirds of posts were coated with the decided resin cement and seated into the post space so that the long axis of the post space was parallel to the long axis of the post. A custom made loading apparatus was used apply a load of $20 \mathrm{~N}$ for 10 minutes. Excess cement was removed using a sponge pellet then, the resin was light cured through the post for 40 seconds using a conventional light curing unit $(600 \mathrm{~mW} / \mathrm{cm} 2$ output; Hilux Ultra Plus, Benlioglu Dental Inc., Ankara, Turkey). After setting, excess cement was removed with a probe and dentin was etched with $37 \%$ phosphoric acid and bonded with Prime \& Bond 2.1 (Dentsply Ind. Com, Petropolis, RJ, Brazil) according to the manufacturer's instructions. Cores were fabricated in a standard manner using core-forming matrixes, which were fabricated using a heat/vacuum tray-forming machine (Ultra-form, Ultradent). The composite (Filtek Z250; 3M ESPE, St. Paul, MN, USA) was placed using the incremental technique. Each increment was light polymerized for 40 seconds $(600 \mathrm{~mW} / \mathrm{cm} 2$ output; Hilux Ultra Plus, Benlioglu Dental Inc., Ankara, Turkey). 
Samples were kept in water at $37^{\circ} \mathrm{C}$ for 30 days and then thermal cycled for 6000 cycles $\left(5^{\circ} \mathrm{C} / 55^{\circ} \mathrm{C}\right)$ for 30 seconds dwell time and 6 seconds transition time.

\section{Retentive force test}

A standard testing machine (Lloyd Instrument, LTD, West Fareham, England) was used to provide a tensile load directed parallel to the long axis of the post at a crosshead speed of $2 \mathrm{~mm} / \mathrm{min}$ to test the retentive force. The core part was grasped with a custom made device. The force $(\mathrm{N})$ required to dislodge each post from its space was recorded. Two-way ANOVA and Tukey's HSD tests were used to analyse the data in this study.

\section{RESULTS}

Mean values \pm standard deviation of retentive strength $(\mathrm{N})$ obtained for fiberreinforced posts bonded to different treated root canal dentin substrate and 2 luting resin cement types are presented in (Table II). The highest retentive strength $(\mathrm{N})$ value recorded with the self-adhesive resin cement was recorded in group Q(QMix-treated, $\mathrm{N})$ while the lowest values were obtained from group $\mathrm{C}$ (no treatment control group, $\mathrm{N}$ ). With the self-etch resin cement, group QMix treated group showed the highest $(\mathrm{N})$ and the control group had the lowest retentive strength value $(\mathrm{N})$. This data shows that there was a significant influence of root canal surface conditioning on the retention of the fiber-reinforced composite resin posts as compared to control group, (Table III). The difference in the retentive strength values among all root canal surface treatment groups (including control) was significant $(\mathrm{P} \leq .05)$ except between group $\mathrm{CH}$ and $\mathrm{E}$. In addition, the use of 2-step self-etch resin cement, as a luting agent, increased 
significantly $(\mathrm{P} \leq .05)$ the retentive strength values of fiber-reinforced composite resin posts in all groups, except control, when compared to 1-step self-adhesive resin cement (Table II).

\section{DISCUSSION}

The results of this in vitro study support the rejection of the null hypothesis: that dentin pretreatment has no influence on the retention of fiber-reinforced posts with composite core luted to different length of remaining coronal stracture with different types of luting resin cements. The results of this study showed significant influence of remaining cronal stracure, root canal dentin surface treatment and the type of luting resin cement, on the retention of the fiber-reinforced composite resin posts with composite resin cores. In addition to the "traditional" smear layer produced by manually or rotary instrumentation of the root canal walls, subsequent preparation of the post space results in an additional and even thicker smear layer composed of debris and gutta-percha/ sealer remnants. These gutta-percha remnants are plasticized by the frictional heat of the drill and may decrease the penetration and chemical interaction between agents used to bond/lute fiber-reinforced composite resin posts. Accordingly, the adhesion of fiber-reinforced posts will be significantly affected. Thus, achieving clean root canal dentin surfaces after mechanical post space preparation seems to be a

crucial step for optimal post retention, particularly when resin cement is used.$^{46}$ The presence of smear layer can cause the resin cement to adhere to relatively weak smear layers instead of the underlying sound dentin, and may result in decreased post retention. Moreover, "failure of adhesion between radicular dentin and resin cements might induce root fracture", where a failed post might act as a "wedge" in the post space. A fundamental pre-requisite for adhesion to 
intra-radicular dentin is represented by the capability of the clinician to obtain a perfectly clean post space. ${ }^{41}$

In a clinical situation, the failure of a post-and-core restoration is a complex result of cyclic loading, materials fatigue, and microleakage. So the restoration can be expected to fail with less loading than was applied in this study.

To enhance the fracture strength of a root canal treated tooth and the retention of the composite resin core to post and root canal dentin, prefabricated fiber-reinforced composite resin posts are luted to dentin using resin cements. ${ }^{19-22}$ The resin/dentin adhesion interface is considered a weak point in when used with fiber-reinforced composite resin post. ${ }^{42}$ When resin cements is used with radicular posts, a maximum bond strength is required between the resin from one side and dentin and post material from the second side. ${ }^{35.37}$ Some studies suggested a pre-treatment with a chelating materials and sodium hypochlorite before post cementation in order to efficiently remove areas that are not necessary for bonding and fiber posts resin cementation, thus enhancing the retention to resin cement. ${ }^{46-48}$ In this study, the highest bond strength values for vertical dislodgment of the fiber-reinforced composite resin posts were recorded for those luted with 2-step self-etch resin cement and $20 \%$ lactic acid-treated dentin compared to those cemented with 1-step self-adhesive cement in the same treatment group and the difference was significant $(\mathrm{P} \leq .05)$. The use of 1-step selfadhesive cement does not completely remove the smear layer from dentin, but rather saturate the smear plug and fix it at the entrance of the dentinal tubules. In contrast, the use of 2-step resin cement that modifies the smear layer and allow for the formation of a relatively thicker hybrid layer with deeper resin tags, resulting in stronger bonds. 
EDTA and CHX solutions could eliminate the thick smear layer present in the canal walls surface and the smear plugs inside dentinal tubules that is formed during post space preparation. This role allows the bonding resins to infiltrate into the dentinal tubules and the intertubular dentin, thus, efficiently seal the tubules and contribute to the bond strength of root canal posts through an efficient micromechanical retention. ${ }^{36}$ However, Burns et al, (1993) reported that EDTA did not increase the retentive strength of the root canal posts. ${ }^{37}$

The lowest bond strength we recorded was of the control subgroups followed by the $37 \%$ phosphoric acid-treated subgroups. It has been reported that the use of phosphoric acid after post space preparation did not remove the natural irregularities in different root canal dentin locations. The presence of these irregularities which cannot be removed by etching may compromise diffusion of adhesive system monomers and affect bond strength. Also pretreatment with phosphoric acid could induce deep demineralization of dentin and prevent proper resin infiltration, producing a defective zone at the base of the hybrid layer, hence compromising the bond. This finding is contradicted by a results of Zhanj L et al , they found that both $35 \%$ phosphoric acid etching and ultrasonic agitation in combination with EDTA/NaOCl irrigation improved the apical push-out strength of the fiber post, regardless of the type of self-etching system used and could be related to different root canal treatment protocol used in this study.$^{49} \mathrm{wThe}$ results of this study revealed significant variation between the interaction of 2 cementation materials with root canal dentin pretreatments, which highlight the crucial role of the luting cement material and dentin conditioning in the success of root canal treated teeth restorations. Thus, it seems that post retention is dependent in combined aspects on; "the micromechanical interlocking, sliding friction, and chemical bonding". ${ }^{49}$ This study presents some limitation regarding the use of 1 type of fiber reinforced composite resin post with only 1 surface treatment. Further study on the retention of different types of fiber reinforced posts could be conducted. 


\section{CONCLUSION}

With the limitation of this study the following could be concluded;1) Luting fiber-reinforced composite resin posts with Rely X unicem or Panavia F2 resin cement after root canal dentin conditioning with either QMix or 17\% EDTA produced significantly higher retention values compared to dentin conditioning with $37 \%$ phosphoric acid. 2) The use of self-etch resin cement to bond fiber-reinforced composite resin posts produced high retentive strength than bonding with self-adhesive resin cement.

\section{ACKNOWLEDGEMENTS}

Author Disclosure Statement: No conflict of interest exists.

\section{REFERENCES}

1. Assif D, Gorfil C. Biomechanical considerations in restoring endodontically treated teeth. J Prosthetic Dent 1994;71:565-7.

2. Morgano SM. Restoration of pulpless teeth: application of traditional principles in present and future contexts. J Prosthetic Dent 1996;75:375-80.

3. Dejak B, Mlotkowski A. Finite element analysis of strength and adhesion of cast posts compared to glass fiber-reinforced composite resin posts in anterior teeth. J Prosthet Dent 2011;105:115-26. 
4. Mangold JT, Kern M. Influence of glass-fiber posts on the fracture resistance and failure pattern of endodontically treated premolars with varying substance loss: an in vitro study. $\mathrm{J}$ Prosthet Dent 2011;105:387-93.

5. Basaran EG, Ayna E, Halifeoglu M. Microleakage of endodontically treated teeth restored with 3 different adhesive systems and 4 different fiber-reinforced posts. J Prosthet Dent 2012;107:239-51.

6. Valdivia AD, Raposo LH, Simamoto-Júnior PC, Novais VR, Soares CJ. The effect of fiber post presence and restorative technique on the biomechanical behavior of endodontically treated maxillary incisors: an in vitro study. J Prosthet Dent 2012;108:147-57.

7. Schwartz RS, Robbins JW Dowel placement and restoration of endodontically treated teeth: a literature review. J Endod2004;30:289-301.

8. Ferrari M, Vichi A, Garcia-Godoy F. Clinical evaluation of fiber-reinforced epoxy resin dowels and cast doweland cores. Am J Dent2000;13:B15-8.

9. Torborner A, Karlsson S, Syverud M, Hensten-Pettersen A. Carbon fiber reinforced root canal dowels. Mechanical and cytotoxic properties. Eur J Oral Sci1996;104:605-11.

10. Chang JW, Soo I, Cheung GS. Evaluation of fiber post-supported restorations under simulated occlusal loading. J Prosthet Dent 2012;108:158-64.

11. Torbjorner A, Karlsson S, Odman PA. Survival rate and failure characteristics for two dowel designs. J Prosthet Dent 1995;73:439- 44.

12. Mendoza DB, Eakle WS, Kahl EA, Ho R. Root reinforcement with a resinbonded preformed dowel. J Prosthet Dent 1997;78:10-14. 
13. Aleisa K, Alghabban R, Alwazzan K, Morgano SM. Effect of three endodontic sealers on the bond strength of prefabricated fiber posts luted with three resin cements. J Prosthet Dent 2012;107:322-6.

14. Bouillaguet S, Troesch S, Wataha JC, Krejci I, Meyer JM, Pashley DH. Microtensile bond strength between adhesive cements and root canal dentin. Dent Mater 2003;19:199-205.

15. Morris MD, Lee KW, Agee KA, Bouillaguet S, Pashley DH. Effects of sodium hypochlorite and RC-prep on bond strengths of resin cement to endodontic surfaces. J Endod $2001 ; 27: 753-7$.

16. Tay FR, Loushine RJ, Lambrechts P, Weller RN, Pashley DH. Geometric factors affecting dentin bonding in root canals: a theoretical modeling approach. J Endod 2005; 31:584-9.

17. Tay FR, Pashley DH. Aggressiveness of contemporary self-etching systems. I: Depth of penetration beyond dentin smear layers. Dent Mater 2001;17:296-308.

18. Susin AH, Vasconcellos WA, Saad JR, Oliveira Junior OB. Tensile bond strength of selfetching versus total-etching adhesive systems under different dentinal substrate conditions. Braz Oral Res. 2007;21:81-6

19. Stockton L. Factors affecting retention of dowel systems: a literature review. J Prosthet Dent $1999 ; 81: 380-5$.

20. Le Bell A, Tanner J, Lassila L, Kangasniemi I, Vallittu P. Bonding of composite resin luting cement to fiber-reinforced composite root canal dowels. J Adhes Dent 2004; $6: 319-25$.

21. Potesta FL, Broome JC, O'Neal SJ, Givan DA, Ramp LC. The effect of etching technique on the retention of adhesively cemented prefabricated dowels. J Prosthodont. 2008 Aug;17(6):445-50. 
22. Ricardo M. Carvalho, Leo Tjäderhane, Adriana P. Manso, Marcela R. Carrilho \& Carlos Augusto R. Carvalho . Dentin as a bonding substrate.Endodontic Topics 2012, 21, $62-88$.

23. De Munck J, Vargas M, Van Landuyt K, Hikita K, Lambrechts P, VanMeerbeek B. Bonding of an auto-adhesive luting material to enamel and dentin. Dent Mater 2004; 20: 963-71.

24. Saleh IM, Ruyter IE, Haapasalo MP, Ørstavik D. The effects of dentine pre-treatment on the adhesion of root canal sealers. Int Endod J2002;35:859-66.

25. Kuah HG, Lui JN, Tseng PS, Chen NN. The effect of EDTA with and without ultrasonics on removal of the smear layer. J Endod 2009;35:393-6.

26. Ayad MF. Lactic acid root canal irrigation for dowel and core treatment: a pilot study. J Prosthet Dent 2004;92:540-5.

27. Eldeniz AU, Erdemir A, Belli S: Shear bond strength of three resin based sealers to dentin with and without the smear layer. J Endod 2005;31:293-6

28. Gwinnett AJ. Altered tissue contribution to interfacial bond strength with acid conditioned dentin. Am J Dent 1994;7: 243-6.

29. Stojicic S, Shen Y, Qian W, Johnson B, Haapasalo M. Antibacterial and smear layer removal ability of a novel irrigant, QMiX. Int Endod J 2012: 45: 363-371

30. Monticelli F, Osorio R, Mazzitelli C, Ferrari M, Toledano M. Limiteddecalcification/diffusion of self-adhesive cements into dentin.JDR. 2008; 87: 974-9.

31. Caiado AC, de Goes MF, de Souza-Filho FJ, Rueggeberg FA. The effect of acid etchant type and dentin location on tubular density and dimension. J Prosthet Dent. 2010;103: 352-61. 
Nakamura T, Wakabayashi K, Kinuta S, Nishida H, Miyamae M, Yatani H. Mechanical properties of new self-adhesive resin-based cement. J Prosthet Dent2010;54:59-64.

32. Goracci C, Raffaelli O, Monticelli F, Balleri B, Bertelli E, Ferrari M. The adhesion between prefabricated FRC dowels and composite resin cores: microtensile bond strength with and without dowel-silanization. Dent Mater2005;21:437-44.

33. Ferrari M, Vichi A, Mannocci F, Mason PN. Retrospective study of the clinical performance of fiber dowels. . Am J Dent 2000;13:9B-13B.

34. Mentink AG, Creugers NH, Meeuwissen R, Leempoel PJ, Kayser AF. Clinical performance of different dowel and core systems- -results of a pilot study. JOral Rehabil1993;20:577-84.

35. Ari H, Yaşar E, Belli S. Effects of $\mathrm{NaOCl}$ on bond strengths of resin cements to root canal dentin. J Endod 2003;29: 248-51.

36. Hayashi M, Takahashi Y, Hirai M, Iwami Y, Imazato S, Ebisu S. Effect of endodontic irrigation on bonding of resin cement to radicular dentin. Eur J Oral Sci 2005;113:70-6.

37. Burns DR, Douglas HB, Moon PC. Comparison of the retention of endodontic dowels after preparation with EDTA. J Prosthet Dent 1993;69:262-6

38. Balbosh A, Kern M. Effect of surface treatment on retention of glass-fiber endodontic dowels. J Prosthet Dent2006;95:218-23.

39. Sahafi A, Peutzfeld A, Asmussen E, Gotfredsen K. Effect of surface treatment of prefabricated dowels on bonding of resin cement. Oper Dent 2004;29:60-8.

40. Akgungor G, Akkayan B. Influence of dentin bonding agents and polymerization modes on the bond strength between translucent fiber dowels and three dentin regions within a dowelspace. J Prosthet Dent 2006;95:368-78.

41. Nergiz I, Schmage P, Özcan M, Platzer U () Effect of length and diameter of tapered posts on the retention. J Oral Rehabil 2002: 29;28-34 
42. Schwartz RS. Adhesive dentistry and endodontics. Part 2: bonding in the root canal system the promise and the problems: a review. J Endod 2006;32:1125-34.

43. Zhang L, Huang L, Xiong Y, Fang M, Chen J, Ferrari M. Effect of dowel-space treatment on retention of fiber dowels in different root regions using two self-etching systems. Eur J Oral Sci 2008;116: 280-6.

44. Nakabayashi N, Kojima K, Masuhara E. The promotion of adhesion by the infiltration of monomers into tooth substrates. J Biomed Mater Res1982;16:265-73.

45. Akgungor G, Akkayan B. Influence of dentin bonding agents and polymerization modes on the bond strength between translucent fiber dowels and three dentin regions within a dowelspace. J Prosthet Dent 2006;95:368-78.

46. Pashley DH, Ciucchi B, Sano H, Horner JA. Permeability of dentin to adhesive agents. Quintessence Int1993;24:618-31.

47. Bouillaguet S, Troesch S, Wataha JC, Krejci I, Meyer JM, Pashley DH. Microtensile bond strength between adhesive cements and root canal dentin. Dent Mater2003;19:199-205

48. Huber L, Cattani-Lorente M, Shaw L, Krejci I, Bouillaguet S. Push-out bond strengths of endodontic dowels bonded with different resin-based luting cements. Amer J Dent2007;20:167-72.

49. Boone KJ, Murchison DF, Schindler WG, Walker WA 3rd. Dowel retention: the effect of sequence of Dowel-space preparation, cementation time, and different sealers. J Endodo $2001 ; 27: 768-71$.

50. Ohlmann B, Fickenscher F, Dreyhaupt J, Rammelsberg P, Gabbert O, Schmitter M. The effect of two luting agents, pretreatment of the post, and pretreatment of the canal dentin on the retention of fiber-reinforced composite posts. J Dent. 2008 ;36:87-92. 
51. Zhang L, Huang L, Xiong Y, Fang M, Chen JH, Ferrari M. Effect of post-space self-etching systems. Eur J Oral Sci. 2008 Jun;116(3):280-6.

52.

FIGURE LEGEND
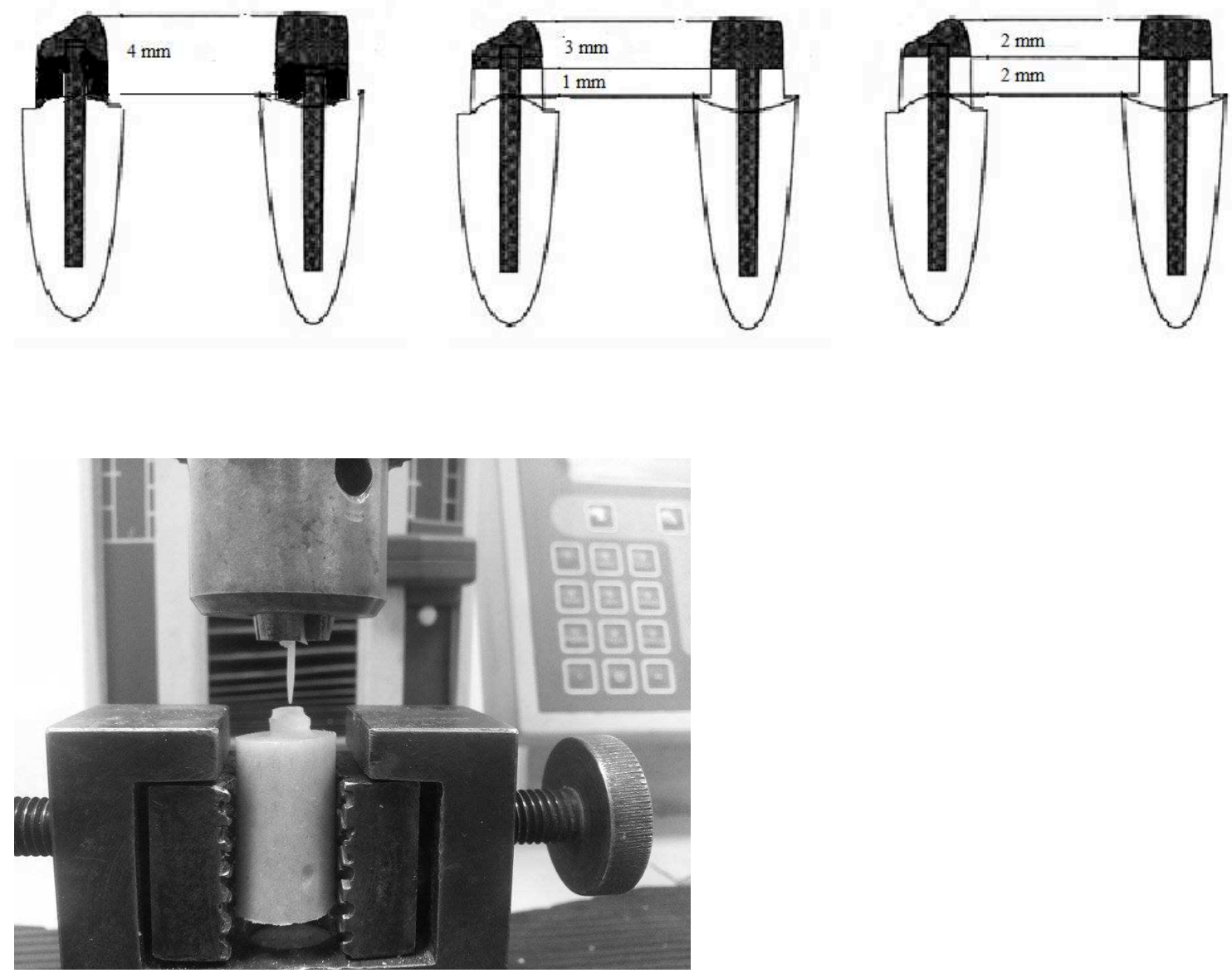


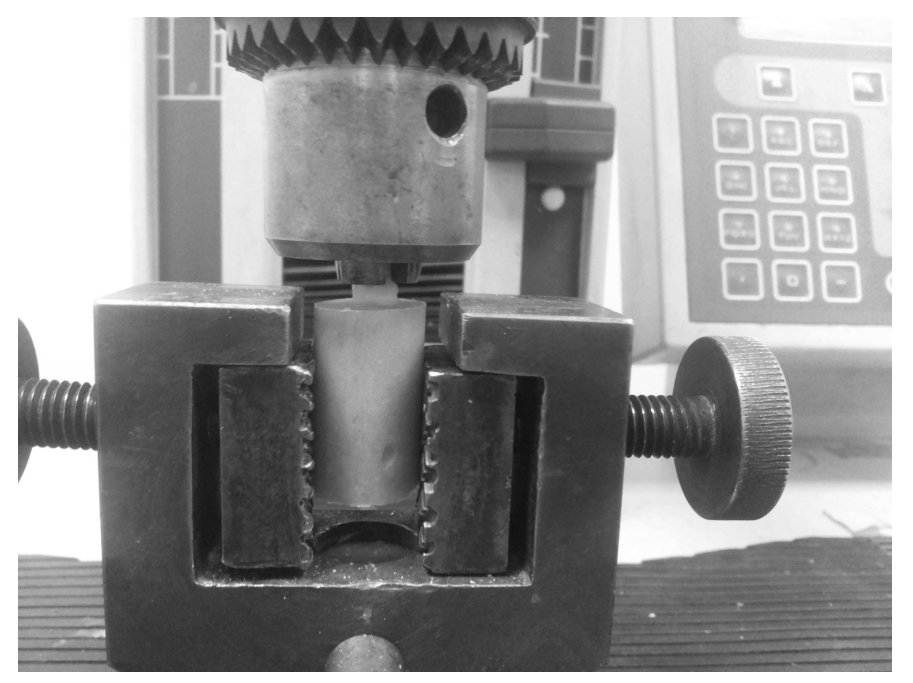

JPD-15-97

Retentive strength of fiber-reinforced composite posts with composite resin cores: Effect of remaining coronal structure and root canal dentin conditioning protocols.

\footnotetext{
ABSTRACT

Statement of problem. The prognosis of a fixed dental prosthesis cemented to endodontically treated teeth is determined by the presence of a ferrule on the tooth, and adhesion of the post in the root canal where the amount of coronal structure and conditioning methods for the canal could be decisive.

Purpose. The purpose of this in vitro study was to test the effect of remaining coronal structure on the retention of airborne-particle abraded fiber-reinforced composite resin posts built up with composite resin cores after the treatment of root canal dentin with different conditioning protocols.
} 
Material and methods. One hundred and fifty extracted human teeth with single root canal space were endodontically treated and divided into 3 groups as follows: Group CEJ: The teeth were sectioned at the level of cementoenamel junction (CEJ), Group CEJ1: The teeth were sectioned $1 \mathrm{~mm}$ above the CEJ, and Group CEJ2: The teeth were sectioned $2 \mathrm{~mm}$ above the CEJ. Each group was further divided into 5 subgroups ( $\mathrm{n}=10$ per group) according to the root canal treatments as follows: Group C: No conditioning (Control); Group PH: Conditioning with 37\% phosphoric acid gel for 15 seconds; Group E: Conditioning with 17\% ethylenediaminetetraacetic acid (EDTA) for 60 seconds; Group CHX: Conditioning with 2\% chlorhexidine (CHX) for 60 seconds; Group Q: Conditioning with combination of 2\% CHX with $17 \%$ EDTA and a surfactant solution for 60 seconds. Glass fiber-reinforced composite resin posts were airborne-particle abraded and luted to the root canal dentin with a self-adhesive resin cement (RelyX Unicem). The retentive force was tested by applying a tensile load parallel to the long axis of these posts at a crosshead speed of $2 \mathrm{~mm} / \mathrm{min}$. Two-way analysis of variance (ANOVA) and the Tukey HSD post hoc test were used to analyze the data.

Results. The highest retention (N) was obtained with the CHX-EDTA conditioned group (374.7 \pm 29.8 ) followed by $17 \%$ EDTA ( $367.9 \pm 33.3)$ conditioning when $2 \mathrm{~mm}$ remaining coronal structure was available. Conditioning with the CHX-EDTA showed comparable retention values to $17 \%$ EDTA conditioned groups that differed significantly compared to $37 \% \mathrm{PH}$ and $2 \% \mathrm{CHX}$ conditioning $(\mathrm{P}<.05)$

Conclusions. Conditioning root canal either with CHX-EDTA or 17\% EDTA delivered superior retention values for fiber-reinforced composite resin posts with composite resin cores that were luted with self-adhesive resin cement to endodontically treated teeth with $2 \mathrm{~mm}$ remaining coronal structure. 
Clinical implications. Conditioning root canal dentin with either CHX-EDTA combination or $17 \%$ EDTA before cementation with self-adhesive resin cement may enhance the retention of fiber-reinforced composite resin posts to the root canal. Endodontically treated teeth with more than $1 \mathrm{~mm}$ remaining coronal structure produced high retentive values compared to tooth with no remaining coronal structure.

\section{INTRODUCTION}

Restoring the endodontically treated tooth can be a challenge for most clinicians, particularly when there is loss of coronal tooth structure. The restoration of endodontically treated teeth with a significant loss of coronal tooth structure may require the placement of a post to ensure an adequate retention of a core foundation..$^{1-4}$ Among different post materials, glass fiber-reinforced composite resin post systems have inherent advantages with respect to their biomechanical properties and their property of increasing light transmission through the root and the gingival tissues ${ }^{5-7}$ Furthermore, they are easy to remove in the event of treatment failure, ${ }^{8}$ eliminate the potential risk of corrosion and allergic reactions associated with metal posts, ${ }^{9}$ and have a low modulus of elasticity that has been reported to reduce root fracture. ${ }^{10,11}$ Glass-fiber composite resin posts are formed of glass fibers, inorganic filler, and resin matrix. Resin cement is usually used to lute these posts in order to increase their retention in the root canal and improve the functional performance of the tooth being restored. ${ }^{12}$ Failure of fiber posts is mainly related to debonding that usually occurs along the post/dentin adhesive interface. Many factors may influence the retention of resin cement luted posts, ${ }^{13,14}$ such as the irrigant used in the root canal preparation, ${ }^{15}$ thick smear layer, and configuration factor defined as the ratio of bonded to unbonded surfaces in post preparations. ${ }^{16}$ Treatment of the smear layer before post cementation 
may be important in achieving high retentive strength levels. The primary objective of applying these agents is to merge the smear layer into the hybrid layer ${ }^{17}$ and facilitate the penetration of adhesives into the dentinal tubules to form an interdiffusion zone between the adhesive material and etched dentin. ${ }^{18-20}$

The use of 35\% phosphoric acid in conditioning root dentin before luting with chemically polymerized adhesive cement was reported to be ineffective or even harmful. ${ }^{21,22}$ The use of fewer acidic agents such as ethylenediaminetetraacetic acid (EDTA) or lactic acid was also considered for conditioning root dentin. ${ }^{23-27}$ These acidic challenges enhance the chemical adhesion between the luting cement and the substrate by partial elimination of the smear layer, leaving the dentinal mineral phase. ${ }^{26,28}$ Recently, a combination of $2 \%$ chlorhexidine (CHX) and 17\% EDTA with surfactants (QMix; Dentsply Tulsa Dental) was introduced for root canal irrigation. ${ }^{29}$ Its manufacturer recommends that it should be used at the end of instrumentation after $\mathrm{NaOCl}$ irrigation. The use of resin cements based on acidic monomers was recommended for fiber-reinforced composite resin posts cementation, as its application is simple and saves chairside-time. ${ }^{29}$ However, because of the need to enhance cement/dentin interaction and eventually the adhesion of resin cements, the smear layer should be eliminated by using an acidic conditioning material. ${ }^{30,31}$ Clinical studies reported debonding of the posts as the most common failure type for restorations placed with adhesively luted fiber posts. ${ }^{32,33}$ As the most common reason for fiber-reinforced post failure is the dislodgement of the post from the root canal, which might occur after years as a result of dynamic mechanical loading, ${ }^{34}$ post retention is generally agreed to be the major factor in the survival of restorations. ${ }^{32}$

Consequently, many studies have focused on the improvement of post retention, including the use of different irrigants in the root canal, pretreatment of the posts and dentin, post 
configuration, or the use of various luting cements. ${ }^{35-49}$ However, the study of the effect of remaining coronal structure, the ideal surface conditioning of the root dentin, and the resin cement needed to improve the retention of posts in one experimental design have not yet been verified. This study aimed to test the null hypothesis that both of the amount of remaining coronal tooth structure and dentin conditioning would not affect the retention of fiber-reinforced composite resin posts with composite resin cores luted with different types of luting resin cements.

\section{MATERIAL AND METHODS}

One hundred and fifty extracted human maxillary anterior teeth were obtained for this study after informed consent from patients with periodontitis and having teeth with grade III mobility. Approval to use human teeth was obtained from the Research Ethics Committee at the Faculty of Dentistry, Mansoura University, Egypt. Power analysis was performed before conducting this study (SAS/STAT 12.1 software; SAS Institute Inc) to determine the number of specimens required in each experimental group in order to determine statistical differences. Teeth selected for this study were free of caries and cracks and had straight roots, with 1 round root canal and fully developed apices. The teeth were cleaned of calculus deposits and soft tissues. After extraction, they were then stored in a $0.1 \%$ thymol solution at $4^{\circ} \mathrm{C}$ to be used for a maximum of 3 months.

The teeth were assigned to 3 groups ( $\mathrm{n}=50$ per group) (Fig. 1) based on the amount of remaining coronal structure: Group CEJ: Anatomical crowns were transversely sectioned at the level of the cementoenamel junction (CEJ) with a diamond rotary cutting instrument (837KR.012; Gebr Brasseler GmbH) under water spray. The sectioned surface was flattened to 
be perpendicular to the longitudinal axis of the tooth with silicon carbide paper (600-grit). Group CEJ1: Anatomical crowns were transversely sectioned $1 \mathrm{~mm}$ coronal to the CEJ as described in Group CEJ. Group CEJ2: Anatomical crowns were transversely sectioned $2 \mathrm{~mm}$ coronal to the CEJ, as described earlier.

After the removal of the pulpal tissue, the root canal form was examined by using an endodontic file (10 K-file; Dentsply Maillefer) through the tooth apical foramen. Canal working length was fixed to be $1 \mathrm{~mm}$ shorter from the apical foramen. A step-back technique was used in this study during root canal preparation. The same operator (SS) performed all root canal preparations with a final file size number 55 (Dentsply Maillefer). In the process of root canal shaping, 5.25\% sodium hypochlorite irrigant was used after each file and up to the final size used, followed by rinsing with distilled water. The canals were then dried with paper points (Dentsply Maillefer). The canals were then obturated by using the lateral condensation technique with gutta percha cones (Dentsply Maillefer) and sealer (AH-Plus; Dentsply DeTrey GmbH). After obturation, the cervical root canal openings were closed with a temporary restorative material (Cavit-G; $3 \mathrm{M} \mathrm{ESPE}$ ), and the teeth were stored at $37^{\circ} \mathrm{C}$ for 7 days at $100 \%$ humidity.

The teeth in Groups CEJ1 and CEJ2 received a $1.2 \mathrm{~mm}$ butt shoulder preparation with rounded inner angles by using a surveyor. The preparations had a convergence of 6 degrees. The finish line of each preparation was at the CEJ. The post space was prepared to the depth of 10 $\mathrm{mm}$ from the CEJ, and an apical seal of $4 \mathrm{~mm}$ of gutta-percha was left untouched. A warm plugger (Sybron Dental Specialties) was used to remove gutta percha up to the specified depth. In order to enlarge the root canals, a low-speed drill provided by the same manufacturer of the post system was used. The canal space was cleaned with a final flush of sterile water and dried with paper points (Dentsply Maillefer). 
The teeth with prepared root canals were divided into 4 groups ( $\mathrm{n}=20$ per group) according to dentin conditioning protocol: Group C: Root canals receiving no conditioning were considered as a control; Group PH: 37\% phosphoric acid gel (Total Etch; Ivoclar Vivadent) was used to etch the root canals for 15 seconds using a syringe and applicator tip followed by an irrigation step with distilled water to remove the etchant excess. Then, the canals were dried with paper points; Group E: Root canals were conditioned with 17\% EDTA (Ethylenediaminetetraacetic acid; Pulpdent) for 60 seconds, rinsed with water and dried with paper points; Group CHX: Root canals were rinsed with 2\% CHX (Chlorhexidine, Gluco-CheX 2\%; PPH Cerkamed); Group Q: Root canals were rinsed with combination of 2\% CHX with 17\% EDTA and a surfactant solution (QMix; Dentsply Tulsa Dental) for 60 seconds, irrigated with water, and dried with paper points.

Fiber-reinforced composite root posts (Postec Plus; Ivoclar Vivadent) of 1.4-mm diameter were selected. Each post was mounted on a custom-made revolving wheel, where each of the posts was airborne-particle abraded with $50-\mu \mathrm{m}$ alumina particles (Heraeus Kulzer) from 4 sides at $250 \mathrm{kPa}$ pressure for 5 seconds. Self-adhesive resin cement (RelyX Unicem; 3M ESPE) was mixed and applied, following the manufacturer's instructions (Table 1). The posts were inserted in a custom-made holder mounted on a surveyor; the apical two thirds of posts were coated with the chosen resin cement and seated into the post space so that the long axis of the post space was parallel to the long axis of the post. A custom-made loading apparatus was used to apply a load of $20 \mathrm{~N}$ for 10 minutes. Excess cement was removed with a sponge pellet. Then, the resin was photopolymerized through the post for 40 seconds with a halogen photopolymerization unit (Output: $600 \mathrm{~mW} / \mathrm{cm} 2$; Hilux Ultra Plus; Benlioglu Dental Inc). After setting, excess cement was removed with a probe, dentin was etched with $37 \%$ phosphoric acid, 
and an adhesive resin (Prime \& Bond 2.1; Dentsply Intl) was applied according to the manufacturer`s instructions. Cores were fabricated in a standard manner using core-forming matrices fabricated with a heat/vacuum tray-forming machine (Ultra-form; Ultradent Products Inc). The composite resin (Filtek Z250; 3M ESPE) was placed incrementally. Each increment was photopolymerized for 40 seconds (Output: $600 \mathrm{~mW} / \mathrm{cm} 2$; Hilux Ultra Plus). The specimens were kept in water at $37^{\circ} \mathrm{C}$ for 30 days and then thermocycled for 6000 cycles $\left(5^{\circ} \mathrm{C} / 55^{\circ} \mathrm{C} ; 30\right.$ seconds dwell time, 6 seconds transition time)

A standard testing machine (Universal Testing Machine; Lloyd Instruments Ltd) was used to apply a tensile load directed parallel to the long axis of the post at a crosshead speed of 2 $\mathrm{mm} / \mathrm{min}$ to test the retentive force of the posts, where the core part was grasped with a custom made device (Fig. 2).

Data were evaluated for homogeneity with the Kolmogorov-Smirnov and Levene normality tests (SPSS v11.0 software for Windows; SPSS Inc). Retentive force data (N) were submitted to 2-way analysis of variance (ANOVA). Multiple comparisons were made with the Tukey HSD post hoc test $(\alpha=.05)$.

\section{RESULTS}

The mean values and standard deviations of retentive forces $(\mathrm{N})$ obtained for the fiberreinforced posts bonded to differently conditioned root canal dentin substrates and the 3 remaining coronal structures are presented in Table 1 and Figure 3. The highest mean retentive strength $(\mathrm{N})$ value was recorded with the remaining coronal structure of $2 \mathrm{~mm}$ in Group Q (374.7 $\pm 29.8 \mathrm{~N})$, while the lowest mean value was obtained from Group C (205 $\pm 11.7 \mathrm{~N})$. Root canal surface conditioning significantly affected the retention of the fiber-reinforced composite resin 
posts compared with the control group. The difference in the retention values among all root canal surface conditioned groups, including the control, was significant $(P<.05)$, except between Groups $\mathrm{Q}$ and $\mathrm{E}(P>.05)$. In addition, the remaining coronal structure significantly affected the retentive strength values of fiber-reinforced composite resin posts in all groups $(P<.05)$.

\section{DISCUSSION}

The results of this in vitro study support the rejection of the null hypothesis that root canal dentin conditioning would not affect the retention of fiber-reinforced posts with composite resin cores luted to different amounts of remaining coronal structure with self-etch adhesive luting resin cement. The results of this study showed significant influence of the amount of remaining coronal structure and root canal dentin surface conditioning on the retention of the fiber-reinforced composite resin posts with composite resin cores.

In addition to the traditional smear layer produced by manually or rotary instrumentation of the root canal walls, subsequent preparation of the post space results in an additional and even thicker smear layer composed of debris and gutta-percha/sealer remnants. ${ }^{41}$ These gutta percha remnants are plasticized by the frictional heat of the drill and may decrease the penetration and chemical interaction between resin based materials used to bond/lute fiber-reinforced composite resin posts. Accordingly, the adhesion of fiber-reinforced posts will be significantly affected. Thus, achieving clean root canal dentin surfaces after mechanical post space preparation is a crucial step for optimal post retention, particularly when resin cement is used. ${ }^{46}$ The presence of a smear layer can cause the resin cement to adhere to relatively weak smear layers instead of the underlying sound dentin and may result in decreased post retention. Moreover, the failure of adhesion between radicular dentin and resin cements might induce root fracture, where a failed 
post might act as a wedge in the post space. A fundamental prerequisite for adhesion to intraradicular dentin is represented by the ability of the clinician to obtain a seamlessly clean post space. ${ }^{44}$

In clinical situations, the failure of a post-and-core restoration is a complex result of cyclic loading, materials fatigue, and microleakage. Thus, the restoration can be expected to fail with less loading than was applied in this study. In order to enhance the fracture strength of a root-canal-treated tooth and the retention of the composite resin core to post and root canal dentin, prefabricated fiber-reinforced composite resin posts should be luted to dentin with resin cements. ${ }^{18-22}$ The resin/dentin adhesion interface is considered a weak link when fiber-reinforced composite resin posts are used. ${ }^{42}$ When resin cements are used with radicular posts, maximum bond strength is required between the resin, the dentin, and the post material. ${ }^{36,38}$ Some studies suggested conditioning root dentin with chelating agents and sodium hypochlorite before post cementation in order to enhance the adhesion of the resin cement. ${ }^{45,46,49}$ In this study, significantly higher retentive strength values were obtained for the vertical dislodgment of the fiber-reinforced composite resin posts cemented to $1 \mathrm{~mm}$ remaining coronal structure compared with those luted to $2 \mathrm{~mm}$ remaining coronal structure when the root canal dentin was conditioned with a combination of $2 \% \mathrm{CHX}$ with $17 \%$ EDTA and a surfactant solution. Previous studies suggest that natural tooth structure provides more bond strength for resisting shear-off forces than core or post materials. ${ }^{5,7}$ The presence of adequate tooth structure with a ferrule at the crown-root interface is critical for the long-term success of the crowned endodontically treated tooth. To improve the integrity of the endodontically treated tooth, a minimum sound dentin height of 1.5 to $2 \mathrm{~mm}$ is required between the core and crown margins to provide support for the crown. ${ }^{40}$ 
EDTA and CHX solutions could eliminate the thick smear layer present in the canal wall surface and the smear plugs inside the dentinal tubules formed during post space preparation. This allows the bonding resins to infiltrate into the dentinal tubules and the intertubular dentin, thus, efficiently sealing the tubules and contributing to the bond strength of root canal posts through efficient micromechanical retention. ${ }^{37,46,49}$ However, Burns et al ${ }^{36}$ reported that EDTA did not increase the retentive strength of the root canal posts.

The lowest retentive strength was recorded for the control subgroups, followed by the $37 \%$ phosphoric acid-conditioned subgroups. The use of phosphoric acid after post space preparation did not remove the natural irregularities in different root canal dentin locations. ${ }^{22}$ The presence of irregularities that cannot be removed by etching may compromise the diffusion of adhesive system monomers and affect the bond strength of the resin cement. Also, pretreatment with phosphoric acid could induce deep demineralization of dentin and prevent proper resin infiltration, producing a defective zone at the base of the hybrid layer that compromises the bond. This finding is contradicted by the study of Zhang et al, ${ }^{43}$ who reported that both $35 \%$ phosphoric acid etching and ultrasonic agitation in combination with EDTA/NaOCl irrigation improved the apical push-out strength of the fiber posts, regardless of the type of self-etching system used. The difference in these results compared with those in this study could be in part attributed to the different root canal treatment protocols used in this study.

The results of this study revealed significant variation between the interactions of remaining coronal structures with root canal dentin conditioning, highlighting the crucial role of coronal structure preservation during endodontic treatment and dentin conditioning in the success of restorations luted to root canal treated teeth. When excellent adhesion is achieved between restorations and the tooth structure, a minimal intervention policy for restoring teeth can 
eventually preserve remaining tooth structure, especially when restoring endodontically treated teeth. Thus, post retention seems to be dependent on the combined aspects of micromechanical interlocking, sliding friction, and chemical bonding. ${ }^{37}$

This study presents some limitations regarding the use of one type of fiber-reinforced composite resin post with one luting cement. Further studies on the retention of different types of fiber-reinforced posts in combination with other self-adhesive cements should verify the results of this study.

\section{CONCLUSIONS}

From this in vitro study, the following could be concluded:

1. Luting fiber-reinforced composite resin posts with self-adhesive resin cement after root canal dentin conditioning with either a combination of $2 \% \mathrm{CHX}$ with $17 \%$ EDTA and a surfactant solution or $17 \%$ EDTA produced significantly higher retention values compared with those with dentin conditioning with $37 \%$ phosphoric acid.

2. The preservation of the remaining coronal structure of endodontically treated teeth increased the retentive strength of airborne-particle abraded fiber-reinforced composite resin posts. 


\section{REFERENCES}

1. Assif D, Gorfil C. Biomechanical considerations in restoring endodontically treated teeth. J Prosthetic Dent 1994;71:565-7.

2. Akgungor G, Akkayan B. Influence of dentin bonding agents and polymerization modes on the bond strength between translucent fiber dowels and three dentin regions within a dowel space. J Prosthet Dent 2006;95:368-78.

3. Mangold JT, Kern M. Influence of glass-fiber posts on the fracture resistance and failure pattern of endodontically treated premolars with varying substance loss: an in vitro study. J Prosthet Dent 2011;105:387-93.

4. Durmuş G, Oyar P. Effects of post core materials on stress distribution in the restoration of mandibular second premolars: a finite element analysis. J Prosthet Dent 2014;112:547-54.

5. Valdivia AD, Raposo LH, Simamoto-Júnior PC, Novais VR, Soares CJ. The effect of fiber post presence and restorative technique on the biomechanical behavior of endodontically treated maxillary incisors: an in vitro study. J Prosthet Dent 2012;108:147-57.

6. Pereira JR, do Valle AL, Shiratori FK, Ghizoni JS, Bonfante EA. The effect of post material on the characteristic strength of fatigued endodontically treated teeth. J Prosthet Dent 2014;112:1225-30.

7. Samran A, Al-Afandi M, Kadour JA, Kern M. Effect of ferrule location on the fracture resistance of crowned mandibular premolars: An in vitro study. J Prosthet Dent 2015 Mar 18. 
8. Ferrari M, Vichi A, Garcia-Godoy F. Clinical evaluation of fiber-reinforced epoxy resin dowels and cast dowel and cores. Am J Dent 2000;13:B15-8.

9. Torborner A, Karlsson S, Syverud M, Hensten-Pettersen A. Carbon fiber reinforced root canal dowels. Mechanical and cytotoxic properties. Eur J Oral Sci 1996;104:605-11.

10. Torbjorner A, Karlsson S, Odman PA. Survival rate and failure characteristics for two dowel designs. J Prosthet Dent 1995;73:439- 44.

11. Chang JW, Soo I, Cheung GS. Evaluation of fiber post-supported restorations under simulated occlusal loading. J Prosthet Dent 2012;108:158-64.

12. Mendoza DB, Eakle WS, Kahl EA, Ho R. Root reinforcement with a resin bonded preformed dowel. J Prosthet Dent 1997;78:10-4.

13. Aleisa K, Alghabban R, Alwazzan K, Morgano SM. Effect of three endodontic sealers on the bond strength of prefabricated fiber posts luted with three resin cements. J Prosthet Dent 2012;107:322-6.

14. Yaman BC, Ozer F, Takeichi T, Karabucak B, Koray F, Blatz MB. Effect of thermomechanical aging on bond strength and interface morphology of glass fiber and zirconia posts bonded with a self-etch adhesive and a self-adhesive resin cement to natural teeth. J Prosthet Dent 2014;112:455-64.

15. Morris MD, Lee KW, Agee KA, Bouillaguet S, Pashley DH. Effects of sodium hypochlorite and RC-prep on bond strengths of resin cement to endodontic surfaces. J Endod 2001;27:753-7. 16. Tay FR, Loushine RJ, Lambrechts P, Weller RN, Pashley DH. Geometric factors affecting dentin bonding in root canals: a theoretical modeling approach. J Endod 2005;31:584-9. 17. Tay FR, Pashley DH. Aggressiveness of contemporary self-etching systems. I: Depth of penetration beyond dentin smear layers. Dent Mater 2001;17:296-308. 
18. Stockton L. Factors affecting retention of dowel systems: a literature review. J Prosthet Dent 1999;81:380-5.

19. Le Bell A, Tanner J, Lassila L, Kangasniemi I, Vallittu P. Bonding of composite resin luting cement to fiber- reinforced composite root canal dowels. J Adhes Dent 2004;6:319-25.

20. Susin AH, Vasconcellos WA, Saad JR, Oliveira Junior OB. Tensile bond strength of selfetching versus total-etching adhesive systems under different dentinal substrate conditions. Braz Oral Res 2007;21:81-6.

21. Potesta FL, Broome JC, O'Neal SJ, Givan DA, Ramp LC. The effect of etching technique on the retention of adhesively cemented prefabricated dowels. J Prosthodont 2008;17:445-50. 22. Carvalho RM, Tjäderhane L, Adriana P, Carrilho M, Carvalho C. Dentin as a bonding substrate. Endodontic Topics 2012;21:62-88.

23. Saleh IM, Ruyter IE, Haapasalo MP, Ørstavik D.The effects of dentine pre-treatment on the adhesion of root canal sealers. Int Endod J 2002;35:859-66.

24. Ayad MF. Lactic acid root canal irrigation for dowel and core treatment: a pilot study. J Prosthet Dent 2004;92:540-5.

25. De Munck J, Vargas M, Van Landuyt K, Hikita K, Lambrechts P, VanMeerbeek B. Bonding of an auto-adhesive luting material to enamel and dentin. Dent Mater 2004;20:963-71.

26. Eldeniz AU, Erdemir A, Belli S. Shear bond strength of three resin based sealers to dentin with and without the smear layer. J Endod 2005;31:293-6.

27. Kuah HG, Lui JN, Tseng PS, et al. The effect of EDTA with and without ultrasonics on removal of the smear layer. J Endod 2009;35:393-6.

28. Gwinnett AJ. Altered tissue contribution to interfacial bond strength with acid conditioned dentin. Am J Dent 1994;7:243-6. 
29. Stojicic S, Shen Y, Qian W, Johnson B, Haapasalo M. Antibacterial and smear layer removal ability of a novel irrigant, QMiX. Int Endod J 2012;45:363-71.

30. Monticelli F, Osorio R, Mazzitelli C, Ferrari M, Toledano M. Limited decalcification/diffusion of self-adhesive cements into dentin. J Dent Res 2008;87:974-9. 31. Caiado AC, de Goes MF, de Souza-Filho FJ, Rueggeberg FA. The effect of acid etchant type and dentin location on tubular density and dimension. J Prosthet Dent 2010;103:352-61.

32. Ferrari M, Vichi A, Mannocci F, Mason PN. Retrospective study of the clinical performance of fiber dowels. Am J Dent 2000;13:9B-13B.

33. Goracci C, Raffaelli O, Monticelli F, Balleri B, Bertelli E, Ferrari M. The adhesion between prefabricated FRC dowels and composite resin cores: microtensile bond strength with and without dowel-silanization. Dent Mater 2005;21:437-44.

34. Mentink AG, Creugers NH, Meeuwissen R, Leempoel PJ, Kayser AF. Clinical performance of different dowel and core systems- -results of a pilot study. J Oral Rehabil1993;20:577-84. 35. Nakabayashi N, Kojima K, Masuhara E. The promotion of adhesion by the infiltration of monomers into tooth substrates. J Biomed Mater Res1982;16:265-73.

36. Burns DR, Douglas HB, Moon PC. Comparison of the retention of endodontic dowels after preparation with EDTA. J Prosthet Dent 1993;69:262-6.

37. Boone KJ, Murchison DF, Schindler WG, Walker WA 3rd. Dowel retention: the effect of sequence of Dowel-space preparation, cementation time, and different sealers. J Endod 2001;27:768-71.

38. Ari $\mathrm{H}$, Yasar E, Belli S. Effects of $\mathrm{NaOCl}$ on bond strengths of resin cements to root canal dentin. J Endod 2003;29:248-51. 
39. Sahafi A, Peutzfeld A, Asmussen E, Gotfredsen K. Effect of surface treatment of prefabricated dowels on bonding of resin cement. Oper Dent 2004;29:60-8.

40. Hayashi M, Takahashi Y, Hirai M, Iwami Y, Imazato S, Ebisu S. Effect of endodontic irrigation on bonding of resin cement to radicular dentin. Eur J Oral Sci 2005;113:70-6.

41. Akgungor G, Akkayan B. Influence of dentin bonding agents and polymerization modes on the bond strength between translucent fiber dowels and three dentin regions within a dowel space. J Prosthet Dent 2006;95:368-78.

42. Balbosh A, Kern M. Effect of surface treatment on retention of glass-fiber endodontic dowels. J Prosthet Dent 2006;95:218-23.

43. Zhang L, Huang L, Xiong Y, Fang M, Chen J, Ferrari M. Effect of dowel-space treatment on retention of fiber dowels in different root regions using two self-etching systems. Eur J Oral Sci 2008;116:280-6.

44. Aleisa K, Al-Dwairi ZN, Alghabban R, Goodacre CJ. Effect of luting agents on the tensile bond strength of glass fiber posts: An in vitro study. J Prosthet Dent 2013;110:216-22.

45. Srirekha A, Rashmi K, Hegde J, Lekha S, Rupali K, Reshmi G. An in vitro evaluation of passive ultrasonic agitation of different irrigants on smear layer removal after post space preparation: a scanning electron microscopic study. J Indian Prosthodont Soc 2013;13:240-6. 46. Wang L, Pinto TA, Silva LM, Araújo DF, Martins LM, Hannas AR, Pedreira AP, Francisconi PA, Honório HM. Effect of 2\% chlorhexidine digluconate on bond strength of a glass-fibre post to root dentine. Int Endod J 2013;46:847-54.

47. de Araújo DF, Chaves LP, Bim O Jr, Pimentel Garcia FC, Ishikiriama SK, Honório HM, Wang L. Influence of $2 \%$ chlorhexidine digluconate on bond strength of a glass-fibre post luted with resin or glass-ionomer based cement. J Dent 2014;42:735-41. 
48. Elnaghy AM. Effect of QMix irrigant on bond strength of glass fibre posts to root dentine. Int Endod J 2014;47:280-9.

49. Pereira JR, da Rosa RA, do Valle AL, Ghizoni JS, Só MV, Shiratori FK. The influence of different cements on the pull-out bond strength of fiber posts. J Prosthet Dent 2014;112:59-63.

Table 1. Mean and standard deviations of retentive strength values $(\mathrm{N})$ of fiber-reinforced composite posts of all groups. Uppercase similar letters show significant differences $(\mathrm{P}<.05)$ and lowercase letters show no significant differences in row $(\mathrm{P}>.05)$.

\begin{tabular}{|c|c|c|c|}
\hline \multirow{2}{*}{$\begin{array}{l}\text { Root dentin } \\
\text { conditioning protocols }\end{array}$} & \multicolumn{3}{|c|}{ Remaining coronal structure } \\
\hline & $\mathbf{0} \mathbf{~ m m}$ & $1 \mathrm{~mm}$ & $2 \mathrm{~mm}$ \\
\hline Control (No treatment) & $195.9 \pm 17.8^{\mathrm{a}}$ & $204.2 \pm 15.2^{\mathrm{a}}$ & $205 \pm 11.7^{\mathrm{a}}$ \\
\hline $37 \%$ phosphoric acid $(\mathrm{pH}=1.5)$ & $243.3 \pm 22.9^{b}$ & $300.1 \pm 28.1^{\mathrm{B}}$ & $334.3 \pm 17.1^{\mathrm{C}}$ \\
\hline $2 \%$ Chlorohexidine $(\mathrm{pH}=7)$ & $295.9 \pm 27.5^{c}$ & $334.2 \pm 40^{\mathrm{d}}$ & $344.7 \pm 35.5^{\mathrm{E}}$ \\
\hline 17\% EDTA $(\mathrm{pH}=0.3)$ & $310.3 \pm 32.9^{\mathrm{e}}$ & $342.8 \pm 38^{\mathrm{f}}$ & $367.9 \pm 33.3^{g}$ \\
\hline $2 \% \mathrm{CHX}+17 \%$ EDTA $(\mathrm{pH}=7.5)$ & $319.7 \pm 17.5^{\mathrm{e}}$ & $351.5 \pm 27.7^{f}$ & $374.7 \pm 29.8^{\mathrm{g}}$ \\
\hline
\end{tabular}


JPD-15-9738 
Table 2. Summary of two-way ANOVA for representation of effect of interactions between root canal dentin surface conditioning method and remaining coronal structure variables on retentive strength of fiber-reinforced composite resin posts.

\begin{tabular}{|c|c|c|c|c|c|}
\hline Source & $\begin{array}{l}\text { Type III Sum of } \\
\text { Squares }\end{array}$ & df & Mean Square & $\mathbf{F}$ & $\mathbf{P}$ \\
\hline $\begin{array}{l}\text { Corrontad } \\
\text { Model }\end{array}$ & $517589.753 \mathrm{a}$ & 11 & 26070607 & $18 \cap 25$ & $\mathrm{n} \cap 1$ \\
\hline Intercept & 13650090.869 & 1 & 13650090.869 & 17735.047 & .001 \\
\hline Conditioning & 429654.510 & 4 & 107413.627 & 139.558 & .001 \\
\hline Coronal & 70258.985 & 2 & 35129.492 & 45.642 & .002 \\
\hline $\begin{array}{l}\text { Conditioning } \\
*\end{array}$ & 17676.259 & 8 & 2209.532 & 2.871 & .006 \\
\hline
\end{tabular}




\section{LEGENDS}

Fig. 1. Schematic diagram representing volume of remaining coronal structures.

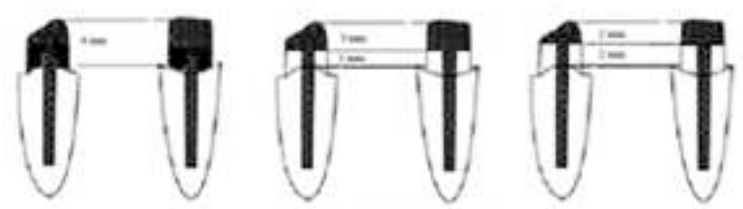

Fig. 2. Standard testing machine used to apply tensile load directed parallel to long axis of post at crosshead speed of $2 \mathrm{~mm} / \mathrm{min}$ to test retentive force. Dislodged post after testing.

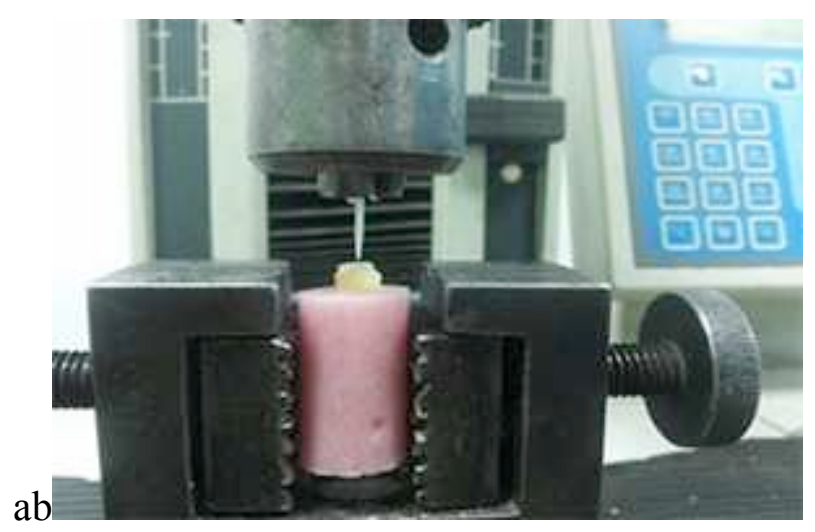


Fig. 3. Retentive strength values of fiber-reinforced composite posts detached from as function of root canal dentin conditioning and volume of remaining coronal structure.

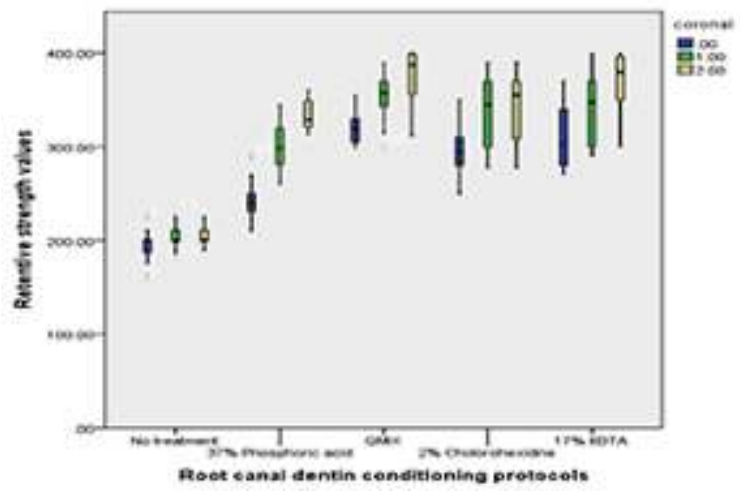

